\title{
O desenvolvimento da negação: proposta de classificação funcional das construções negativas em desenvolvimento
}

DOI: http://dx.doi.org/10.21165/el.v48i2.2181

\section{Angelina Nunes de Vasconcelos ${ }^{1}$}

\section{Resumo}

O presente artigo se caracteriza como estudo longitudinal de duas crianças, uma brasileira e uma francesa, e propõe, a partir do trabalho de Beaupoil-Hourdel (2013), um sistema de classificação sócio-pragmático das negações desenvolvido por elas. As seguintes categorias são consideradas: rejeição/recusa; expectativas insatisfeitas; ausência/desaparição; proibição/comando; oposição/correção; rogativa negativa; negação epistêmica; negação funcional. Destaca-se que a rejeição/recusa é a primeira função a emergir na fala de ambas as crianças, ao passo que a ausência/desaparição é inesperadamente mais tardia. Em adição, observa-se o aumento progressivo da complexidade das negações produzidas pelas duas crianças por meio da inclusão de pronomes pessoais em seus enunciados, além da introdução de variações nas partículas negativas utilizadas.

Palavras-chave: negação; aquisição da linguagem; Francês; Português.

1 Universidade Federal de Alagoas (UFAL), Maceió, Alagoas, Brasil; vasconcelos.angelina@gmail.com; https://orcid.org/0000-0003-4376-4740 


\title{
The development of the negation: proposal of functional classification of the negative constructions in development
}

\begin{abstract}
This paper aims to study the development of negation based on longitudinal data of two children, a Brazilian one and a French one. In the present study, we proposed, based on the work of Beaupoil-Hourdel (2013), a system of socio-pragmatic classification of negations. The following categories are considered: rejection / refusal, unrealized expectations, absence / disappearance, prohibition / order, opposition / correction, epistemic negation and functional negation. This work highlights similarities in the two cases, such as the observation that the rejection / refusal function was the first to be produced by both children, while the absence / disappearance is unexpectedly later. In addition, we observe the progressive complexation of the negations produced by the two children through the inclusion of personal pronouns in their utterances, as well as through the introduction of variations in the used negative particles.
\end{abstract}

Keywords: negation; language acquisition; French; Portuguese.

\section{Introdução}

O presente artigo focaliza negações produzidas por uma criança brasileira e também por uma criança francesa em seus primeiros 32 meses de vida, em situação de interação com seus pais. A negação é aqui focalizada por constituir aspecto importante no processo de aquisição da linguagem, permitindo à criança posicionar-se na interação, bem como possibilitando deslocamento dos lugares discursivos ocupados pela criança, opondo-se aos pais (DEL RÉ; HILÁRIO; VIEIRA, 2012; LEITÃO, 2012). Ressalta-se que a análise de duas crianças que adquirem línguas distintas (Português Brasileiro e Francês) objetiva adicionar o elemento da variabilidade translinguística, possibilitando a observação de especificidades linguísticas no processo de emergência da negação em duas línguas tipologicamente semelhantes (ambas românicas), mas que apresentam distinções em níveis prosódico, lexical, morfológico e sintático.

Impactos de tais especificidades no processo de aquisição da linguagem foram anteriormente assinalados por Konopczynski (1990), que observou como o alongamento final que caracteriza a última sílaba do grupo rítmico em francês é rapidamente adquirido pela criança por volta dos 16 meses de idade, enquanto a aquisição de características rítmicas e acentuais por crianças de línguas marcadas por acento móvel é mais lenta (por volta dos 36 meses). No que diz respeito especificamente à negação, podemos supor que os diferentes modos pelos quais ela é construída em Português e em Francês podem produzir consequências no processo de aquisição. A título de exemplo, destacase como a negação em Português apresenta três possibilidades de estrutura distintas: 
partícula negativa antes do verbo, partícula negativa antes e após o verbo, partícula negativa somente após o verbo (ARMSTRONG; BERGMANN; TAMATI, 2008). A negação em Francês, no que diz respeito à sintaxe, é frequentemente marcada por meio dos advérbios "ne ... pas" que envolvem o verbo - "ne (verbo) pas"-, ou apresentam-se em posição adjacente quando diante de verbos no infinitivo (ne pas finir - não terminar) (LACHERET-DUJOUR; BEAUGENDRE, 1999; KOCHAN, 2008).

A opção pela realização da análise destes dois casos particulares é pautada na preocupação em selecionar casos que apresentem elementos heterogêneos do fenômeno estudado, observando como este fenômeno discursivo (negação) mobiliza diferentes elementos linguísticos, gestuais e contextuais nestas duas línguas e culturas que são distintas, mas apresentam também similaridades e possibilitam pontos de comparação entre elas.

\section{Negação}

Diversas tipologias e classificações foram desenvolvidas na tentativa de delimitar o curso de desenvolvimento da negação, entretanto, tais categorizações usualmente fundamentam-se em elementos sintáticos e semânticos, por vezes ignorando as modalidades gestuais e os componentes prosódicos em crianças bem pequenas.

Como exemplo, destaca-se o trabalho de categorização de McNeill, D. e McNeill, N. (1968) sobre os primeiros marcadores de negação produzidos por uma criança japonesa (a partir dos dois anos e três meses de idade). Os autores concentram-se na emergência das funções semânticas da negação no discurso infantil, afırmando que seu surgimento se dá na seguinte ordem: não existência, negação não-implicada, rejeição e negação implicada (PEA, 1980).

De maneira semelhante, Bloom (1970), a partir da análise de aspectos sintáticos e semânticos da negação no discurso de três crianças de língua inglesa e retomando "os atos de fala" de Searle (não-existência/existência, recusa/aceitação e rejeição/afırmação), postula o surgimento de três categorias semânticas de maneira sucessiva no discurso infantil: a não-existência (quando um referente, que se esperava presente no contexto da interação, não surge), a rejeição (quando um referente presente, ou em iminência de surgir, é rejeitado pela criança) e a recusa (predicado negado). A autora cria também um sistema de classificação composto por dois estágios: o primeiro seria caracterizado pelo surgimento das negações anafóricas e não-anafóricas e o segundo surgiria quando a criança se torna capaz de exprimir sintaticamente recusa e rejeição (BLOOM, 1970; PEA, 1980). 
Entretanto Wode (1977), criticando os modelos anteriores aos dele justamente por não considerarem aspectos entoacionais ou as intenções comunicativas infantis, propõe um novo modelo em quatro estágios: no primeiro, a negação seria produzida a partir da produção de uma palavra isolada (usualmente "não"); no segundo, a negação seria expressa a partir de mais de uma palavra em posição externa ao enunciado; numa terceira etapa, a negação surgiria no interior do enunciado; e na quarta e última etapa, a negação seria corretamente utilizada, aproximando-se das produções adultas (KOCHAN, 2008; DODANE; MASSINI-CAGLIARI, 2010).

Ressalta-se que os modelos de Wode (1977), Kochan (2008) e Dodane e Massini-Cagliari (2010) se restringem à análise da produção de sentenças negativas por crianças, ignorando os momentos iniciais do processo de aquisição, o que pode explicar, em alguma medida, a ausência de destaque aos marcadores prosódicos bem como os aspectos gestuais.

Abordando a relação fala adulta e produção infantil, Cameron-Faulkner, Lieven e Theakston (2007) focalizam o desenvolvimento da negação na interação adulto-criança com crianças norte-americanas entre dois e três anos de idade. Segundo os autores, o uso da negação pela criança apresenta trajetória de desenvolvimento que parece acompanhar o modo como os marcadores de negação surgem progressivamente no discurso da mãe (no, not, can't, won't, don't, nesta ordem). A partir deste estudo, enfatizam a importância do input, afirmando que os marcadores de negação e funções negativas utilizadas pela mãe (não-existência, rejeição, proibição) vão influenciar/determinar o processo de aquisição da negação infantil.

Focalizando as diferentes funções de negações produzidas por crianças, BeaupoilHourdel (2013) desenvolve um sistema de classificação sócio-pragmático para os valores semânticos destas negações, construindo as seguintes categorias: rejeição/recusa, expectativas insatisfeitas (inabilidade/falha), não-presença/desaparição, proibição/ comando, oposição/correção, rogativa negativa, negação epistêmica e negação funcional, conforme descrito a seguir:

Rejeição/recusa: pode ser subdividida enquanto recusa de uma pessoa, atividade, proposição, entidade, interrupção de uma ação ou continuidade de uma atividade. A diferença entre recusa de uma atividade ou ação consiste no valor atribuído à ação. Se a ação ou proposta de ação comporta a proposição de uma atividade (oferta de uma bola com a intenção de dar início a um jogo), ela deve então ser classificada como rejeição de atividade. A recusa de uma proposição diferencia-se da recusa de uma atividade, sendo definida como recusa de proposição formulada verbalmente sem apresentação de objeto. A recusa de uma entidade, ao contrário, consiste na recusa de um objeto que tenha sido proposto sem a intenção de dar início a um jogo ou atividade. 
Expectativas insatisfeitas: abrange referências ao não/mau funcionamento de um objeto, bloqueio de uma atividade ou desapontamento. Pode ser subdividida em falha ou inabilidade: falha relaciona-se ao contexto exterior à criança (algo no mundo que não funciona como esperado, algo que a criança esperava, mas não acontece) e inabilidade diz respeito à criança.

Ausência/desaparição: pode ser relacionada à noção de expectativas insatisfeitas, pois também faz referência a situações de conflito entre o que a criança espera e a realidade. Neste caso, objetos ou pessoas que estavam anteriormente presentes, ou habitualmente presentes, ou das quais se antecipava a presença de alguma maneira, mas estão ausentes.

Proibição/comando: ordens e/ou interdições que objetivam parar ou deter a criança ou ações nas quais ela está engajada. Pode ser também classificada como autoproibições, proibições que são produzidas em monólogo quando a criança se aproxima de objeto perigoso/proibido, por exemplo.

Oposição/correção: situações de desacordo entre interlocutores, negações utilizadas para indicar discordância ou contradição (somente possível para a criança quando esta começa a considerar a opinião, crenças e pressuposições de seu interlocutor).

Rogativa negativa: termos com conotação negativa, como onomatopeias e interjeições, por exemplo, eca! ou urg! ôxe!

Negação epistêmica: expressão de falta de conhecimento ou afirmação de que não possui determinado conhecimento.

Negação funcional: produção de uma declaração negativa para a qual se pode traçar um valor de verdade correspondente: negação dependente de interação com interlocutor, que pode ocorrer como resposta a proposições, a perguntas do tipo sim/não, ou declarações. Corresponde a ato de fala assertivo, quando o falante não admite/não quer que o interlocutor mantenha determinada crença.

A partir destas categorias e fundamentando-se no trabalho realizado por BeaupoilHourdel, Morgenstern e Boutet (2016), busca-se definir e distinguir, a partir de uma abordagem multimodal, as rejeições, recusas e protestos infantis - funções negativas que emergem no discurso da criança antes do aparecimento das primeiras palavras. Para tanto, acompanham uma criança monolíngue inglesa dos 10 meses aos 04 anos de idade. De maneira geral, traçam o curso de desenvolvimento infantil que se caracteriza pela passagem de canais visuais de comunicação a canais auditivos, bem como pela transformação de mecanismos não-simbólicos de comunicação em simbólicos (arbitrários). 
De acordo com o modelo de Beaupoil-Hourdel, Morgenstern e Boutet (2016), a recusa surgiria como resposta a uma proposta formulada pelo interlocutor, ocorrendo antes do início da ação/atividade proposta. Nesta situação, a criança faria uso mais frequentemente de modalidades verbais de comunicação. A rejeição seria desencadeada pela iniciação ou menção de iniciação de determinada ação e, neste caso, a rejeição infantil objetiva a desconstrução da proposta e evita que determinado evento aconteça. A criança não somente recusa a atividade, mas mostra sua discordância para com o interlocutor, utilizando, mais frequentemente, gestos. Por fim, o protesto seria consequência do desejo da criança de interromper a atividade na qual já está envolvida, sendo também veiculado especialmente a partir de gestos. Desse modo, rejeições, recusas e protestos são produzidos em diferentes contextos e por meio de diferentes modalidades expressivas. Adicionalmente, observa-se que as produções infantis parecem passar da ação ao gestual e, por fim, ao verbal. Deste modo, tais modalidades inscrevem-se em um contínuo evolutivo que vai de ações reflexas, passando a ações controladas, a gestos convencionais, a mímicas faciais (franzir o cenho, por exemplo) e, por último, fala e entonação.

Fundamentando-se nestas observações, apresenta-se aqui uma aplicação desta proposta de classificação funcional das construções negativas em dois casos, uma criança brasileira e uma criança francesa, nos momentos iniciais do processo de aquisição.

\section{Participantes e registro dos dados}

O presente estudo caracterizou-se pelo acompanhamento longitudinal de uma criança (sexo masculino) monolíngue brasileira (falante de Português) durante seus 32 primeiros meses de vida, registrada a partir de 04 semanas até os 2 anos e 8 meses de idade (as análises focalizaram o período entre 6 e 32 meses), em situações naturalísticas de interação com seus familiares. A criança observada, V., é filho único de uma família de nível socioeconômico médio da cidade de Maceió-AL (nordeste do Brasil). Além da criançaalvo, os participantes do estudo incluem adultos que interagiram com ele durante as observações: pais, tios e avós. Os dados de $V$. foram registrados mensalmente a partir da quarta semana até os 32 meses de vida, em sessões de duração variável entre 30m-1h.

Em seguida, dados de uma criança (sexo feminino), monolíngue francesa (falante de Francês), foram também analisados. Os dados de M., criança monolíngue francesa de família de nível socioeconômico médio da cidade de Paris-FR, foram filmados pela pesquisadora Martine Sekali, professora da universidade Paris-Ouest Nanterre La Défense (Paris), mensalmente a partir dos onze meses de idade da criança, e a cada três meses a partir dos 4 anos de idade (somente os dados até 32 meses de idade foram aqui analisados). Cada registro possui uma hora de duração e também abarca situações naturalísticas que pertencem a seu cotidiano. Os dados pertencem ao grupo Colaje, coordenado pela Profa. Dra. Aliyah Morgenstern, e estão disponíveis na plataforma 


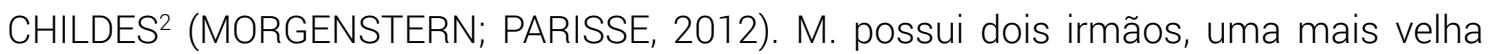
(11 anos de diferença) e um irmão mais novo, que nasceu no decorrer das filmagens, quando M. tinha 1;06 anos. Ambas as crianças não possuem nenhum comprometimento linguístico-cognitivo.

Todos os dados aqui analisados foram transcritos a partir do programa CLAN, que permite o alinhamento entre cada enunciado transcrito e sua realização em vídeo e/ou áudio, possibilitando a visualização da relação entre elementos linguísticos e extralinguísticos. Os dados de M. encontram-se já transcritos na plataforma CHILDES- "Child language data exchange system" em Francês. Os dados de V. foram transcritos da mesma maneira no programa CLAN, a partir do sistema CHILDES, sistema que normatiza regras de transcrição de dados de linguagem da criança, facilitando seu compartilhamento e análise em diferentes línguas.

\section{Negação e suas funções}

Objetivou-se classificar nesta seção as produções negativas verbais e gestuais produzidas pelos adultos e pelas crianças de acordo com suas funções a partir de um sistema de classificação sociopragmático desenvolvido nos trabalhos de Beaupoil (2013) e Kochan (2008).

\section{Produções negativas da mãe de V}

Partindo da perspectiva segundo a qual a linguagem é construída em interação e observando o papel da fala dirigida à criança, observou-se aqui como o adulto adapta sua fala à criança, especialmente em situações de negação, fazendo uso de contornos de entonação e qualidade de voz específicas. Para tanto, destaca-se o papel do manhês no processo de aquisição da linguagem, como discutido por Scarpa e Fernandes-Svartman (2012, p. 4-5):

\footnotetext{
A FDC 3 /manhês faz, a nosso ver, mais do que ser o pano de fundo, o cenário de interação social, para a fala que traria consigo a língua materna. Recorta, contém, salienta, cerca as manifestações orais ou gestuais do bebê, oferece uma sintaxe (embora parcial), expandindo, retomando as manifestações vocais do bebê pré-verbal, assim como o fará, mais tarde, com as verbalizações do bebê que começa a produzir um léxico primitivo.
}

2 http://childes.psy.cmu.edu/data/Romance/French/

3 Fala dirigida à criança. 
Nesse sentido, observamos as características das negações produzidas pelos pais quando em interação com a criança.

No total, 50 produções da mãe de V. foram analisadas; embora seja possível observar também negações produzidas pelo pai (2) e pela avó da criança (2); as negações produzidas pela mãe são as que surgem de maneira mais frequente nos vídeos analisados. Foram delimitadas situações nas quais a mãe de V. enunciava "não" ou construía negações a partir de gestos e/ou elementos contextuais. Tais produções foram subdivididas da seguinte maneira: "nãos" produzidos de maneira isolada (10); outros monossílabos - como "êpa" e "ei"(11); Tininho (1), apelido da criança dito uma vez pela mãe durante repreensão; enunciados contendo a palavra "não" (21) e enunciados negativos que não continham a palavra "não" (7), como ordens que se opunham à ação da criança - "tire da boca mocinho" - ou caracterizações negativas das ações infantis, como "coisa feia mamãe".

Inicialmente, chama a atenção que a maior parte das negações produzidas pela mãe de $\checkmark$ caracterizaram-se pela palavra "não" de maneira isolada ou no interior de enunciados - 31 produções. No que diz respeito às funções, dois tipos foram observados: proibições/ comandos, quando a mãe de $\mathrm{V}$. o proíbe de realizar determinadas ações ou ordena que a criança "desfaça" ação realizada, por exemplo, "tire da boca mocinho", e rejeições, mas frequentemente rejeições de ações, quando a mãe de $V$ realiza negações que se dirigem a ações realizadas pela criança, normalmente quando a criança realiza ação anteriormente proibida, por exemplo, levar um objeto à boca.

De maneira geral, a grande maioria dos monossílabos (incluindo o não) foram produzidos com contorno ascendente (15 de 21), ressaltando-se que dois "não" não puderam ser analisados em decorrência de sobreposição de vozes durante a gravação. Somente 4 monossílabos (nãos) foram produzidos com contorno ascendente-descendente.

Todos os monossílabos foram utilizados para produzir rejeições, ou seja, foram utilizados pela mãe de V. Para rejeitar ação realizada pela criança, na grande maioria dos casos, ações que já haviam sido anteriormente proibidas por ela (levar um objeto à boca ou retirar objetos do lugar). Tais produções parecem surgir, portanto, em contextos de repreensão, quando a criança realiza ação anteriormente proibida por sua mãe, que tenta fazê-lo encerrá-la. Em tais situações, a mãe de V. produz monossílabos com entonação ascendente, aparentemente na tentativa de atrair sua atenção, fazendo-o parar, comunicando ao mesmo tempo sua oposição. Nestes contextos, observa-se também uso de alongamentos vocálicos nas vogais silábicas de glides: "e:i; nã:o". Em oposição, o contorno ascendente-descendente caracteriza majoritariamente os enunciados produzidos com a palavra "não" (não pode não jogar as pedrinhas), parecendo distinguir proibições de maneira geral. 
Como exemplo, apresentamos, a seguir, uma situação registrada quando a criança estava com 11 meses de idade e brincava com algumas pedras do jardim. Nela, é possível observar os dois tipos de contorno produzidos pela mãe de $\mathrm{V}$. na mesma situação. Inicialmente, ela produz enunciado negativo, formulando uma proibição, em seguida, como a criança realiza a ação que havia sido proibida, a mãe de $\vee$ rejeita sua ação fazendo uso de monossílabo, ilustrando, portanto, na mesma situação, os dois tipos de enunciados observados nas negações da mãe de $\mathrm{V}$ :

\section{(14) Episódio 18 - Mãe repreende V (08-11-12/11 meses)}

1. ${ }^{\star} \mathrm{CHI}: 0$.

2. \%act: $\mathrm{CHI}$ tira algumas pedrinhas do canteiro e as joga no chão

3. *MOT: cadê a vó?

4. *MOT: Não pode não jogar as pedrinhas tá bom?

5. ${ }^{\star} \mathrm{CHI}: 0$.

6. \%act: $\mathrm{CHI}$ continua derrubando as pedrinhas no chão.

7. *MOT: êpa [=!]

8. *MOT: Tininho $[=!]$

9. ${ }^{\star} \mathrm{CHI}: 0$.

10. \%act: CHI volta-se para MOT e a olha, ainda brinca com as pedras

11. *MOT: Filho não pode.

Inicialmente, observa-se que a frase "não pode jogar as pedrinhas" expressa uma proibição. Em seguida, como a criança volta a realizar a ação interditada, sua mãe enuncia "êpa", em rejeição, parecendo repreendê-la, chamando a atenção de V. Após esta produção, a criança efetivamente volta seu olhar para a mãe.

A presente análise sugere como a distinção entre funções negativas pode ser construída a partir de elementos prosódicos, evitando o uso de estruturas sintáticas complexas quando em interação com a criança. Mudanças de entonação parecem ser utilizadas para sinalizar mudança de tema (negação), sinalizando de maneira conclusiva que determinada ação ou comportamento infantil deve ser finalizado.

\section{Produções negativas de V}

No total, 61 produções da criança foram analisadas. Delimitamos situações nas quais a mãe de V. interpreta suas produções como protestos, oposições e, posteriormente, como negações, a partir do segundo ano de vida, quando estas se tornam mais complexas no 
nível verbal. A partir desta classificação, observou-se que grande parte das produções de $V$ são classificadas como rejeição/recusa (40 produções), situações nas quais os pais interpretam que $\mathrm{V}$. rejeita uma proposição como tomar banho ou emprestar um brinquedo, por exemplo. As rejeições de $\vee$ foram produzidas principalmente por meio da palavra "não" ou de aproximações desta palavra como "ã" e "nã". Somente a partir dos 29 meses de idade é que as funções das produções negativas de $V$. começam a diversificar-se. Neste momento, surgem oposição/correção (14), proibição/comando (3), negação epistêmica (3) e ausência/desaparição (1).

Observa-se que a maioria das negações de $\mathrm{V}$. são caracterizadas pela rejeição/recusa (40), sendo possível estabelecer paralelo entre suas negações e as de sua mãe, que são também majoritariamente caracterizadas por esta função (31 de 50 produções são rejeições). Do ponto de vista prosódico, as produções de $V$. também se aproximam daquelas produzidas por sua mãe, caracterizando-se principalmente por movimentos ascendentes-descendentes (30 produções). Entretanto, diferentemente do que pudemos observar nas negações de sua mãe, este tipo de contorno não parece caracterizar uma função específica nas negações da criança, mas está presente em todas as funções negativas produzidas por ela.

De maneira geral, as negações infantis neste período são inicialmente utilizadas para rejeitar e opor-se às proposições e ações parentais, entretanto, posteriormente (a partir dos 29 meses de idade), a criança começa a produzir negações epistêmicas, funcionais e de ausência/desaparição, produzindo, portanto, proposições negativas e não somente reagindo às proposições de seus pais. Neste momento, a criança realiza constatações sobre si mesma e seu desconhecimento (negação epistêmica) e constatações sobre ausência de objetos do ambiente (ausência/desaparição). Observa-se então o desenvolvimento das negações infantis não somente a partir do aumento de sua complexidade linguística, mas também a partir do desenvolvimento das funções negativas utilizadas, que passam de reações às ações parentais a proposições negativas. Vasconcelos e Leitão (2016) realizam observação semelhante a partir da análise de oposições infantis, concluindo que há deslocamento do lugar discursivo atribuído à criança, que deixa de ser posicionada apenas no lugar de oponente, para ocupar também o lugar de proponente na interação, agindo sobre o ambiente a partir de um "ponto de vista próprio". Neste momento, a criança não só reage conforme as situações criadas pelos pais, mas toma a iniciativa de agir, mobilizando aspectos do ambiente em proposições muitas vezes negativas. Variações ainda mais amplas das funções negativas utilizadas pela criança podem ser observadas nos dados da criança francesa apresentados a seguir.

\section{Produções negativas da mãe de M}

No total, 98 negações da mãe de $\mathrm{M}$ foram analisadas. As principais funções negativas utilizadas foram: proibição/comando (36), oposição/correção (26) e rejeição/recusa (20), seguidas por expectativas insatisfeitas (5), ausência/desaparição (4), negação funcional (4), 
negação epistêmica (2) e rogativa negativa (1). Inicialmente, destaca-se que as funções proibição/comando e rejeição/recusa são também as mais frequentemente utilizadas pela mãe de $V$, caracterizando as negações dirigidas às crianças neste período nos dois casos. Observa-se, assim, que as duas mães proíbem determinados comportamentos e rejeitam ações infantis que seguem na direção contrária à das proibições estabelecidas. Ressalta-se, entretanto, que as produções da mãe de M. apresentaram número muito maior de funções negativas (cobrindo todas as funções negativas aqui estudadas) do que aquelas utilizadas pela mãe brasileira, embora em quantidades menos expressivas. No que diz respeito às negações mais frequentemente utilizadas, é possível observar semelhanças nos dois casos.

No que diz respeito à caracterização prosódica das negações, novamente observa-se maior diversidade nas produções da mãe francesa quando comparada às produções da mãe brasileira, embora semelhanças importantes sejam encontradas dentre os elementos mais frequentemente presentes nos dois casos. Destaca-se, especificamente, a presença expressiva de curvas ascendentes-descendentes nas negações das mães brasileira (22 de 50 produções) e francesa (30 de 98 produções). Observa-se também que a curva ascendente-descendente é o único elemento presente em todas as funções negativas produzidas.

\section{Produções negativas de $M$}

No que diz respeito às produções de $M$., um grande número de negações pode ser observado. Para este trabalho, 462 negações de M. foram consideradas, ressaltando-se que este número elevado é também consequência da quantidade e tamanho dos vídeos franceses, que ultrapassam os dos brasileiros. De maneira geral, as produções de M. são especialmente desenvolvidas, tendo sido objeto de diversos trabalhos, inclusive sobre a negação (DODANE; BEAUPOIL; DEL RÉ; BOUTET; MORGENSTERN, 2014; DODANE; MASSINI-CAGLIARI, 2010).

Grande parte das negações de M. foram rejeição/recusa (115 negações), sendo esta também a função mais frequentemente produzida pela criança brasileira, seguida por expectativas insatisfeitas (inabilidade/falha) (86), oposição/correção (77), negação funcional (74), negação epistêmica (65), ausência/desaparição (29), proibição/comando (14) e rogativa negativa (2). Observa-se, deste modo, grande variedade nas funções negativas utilizadas pela criança. Tais como as produções de sua mãe, as negações infantis cobrem todas as funções aqui estudadas, embora as funções mais frequentemente produzidas coincidam com as da criança brasileira.

No que diz respeito à caracterização prosódica geral das negações, o movimento ascendente-descendente é novamente o mais frequentemente observado (caracterizando 210 negações), estando presente em todas as funções negativas produzidas. Contornos descendentes (67) e ascendentes (55) são também frequentemente produzidos. 
Observando as produções das duas crianças (brasileira e francesa), concluímos que, independentemente da língua, a função rejeição/recusa é a primeira a ser expressa, conforme também observado por estudos clássicos sobre a tipologia e aquisição da negação (BLOOM, 1970; PEA, 1980). Nos dados aqui analisados, a rejeição é inicialmente expressa pela criança francesa a partir de marcadores simples como "non". O marcador de negação "pas" surge na expressão da rejeição a partir dos 23 meses, em enunciados como "non pas avec (bro)colis" (não com o brócolis) quando a criança rejeita a comida oferecida pela mãe. Expressões mais complexas como "je veux pas" (eu não quero) surgem aos 25 meses, com a utilização de pronome pessoal je (eu). Ressalta-se que é exatamente aos 25 meses que o pronome pessoal je emerge nas produções de $\mathrm{M}$. e que a utilização do pronome moi atinge seu pico (93 produções), conforme relatado por Dodane e Massini-Cagliari (2010), contribuindo para o desenvolvimento da negação, permitindo à criança posicionar-se na interação e construir seu ponto de vista.

Para a criança brasileira, a expressão da rejeição começa também com produções que se aproximam do não como "na" e "ã" e o "não", que é foneticamente produzido aos 16 meses. A expressão da negação de $V$. torna-se mais complexa aos 29 meses com o enunciado "esse não", quando a criança utiliza o pronome demonstrativo esse para fazer referência ao objeto específico que rejeita (neste caso, um brinquedo oferecido por sua mãe). A utilização de pronomes pessoais nas negações registradas de $V$. é observada aos 29 meses, quando a criança enuncia "a num sei mamãe" utilizando a vogal "a" como preenchedor (filler), que substitui o pronome pessoal "eu".

A função ausência/desaparição é expressa apenas uma vez pela criança brasileira durante o período observado, aos 29 meses, a partir da expressão "sem a vaquinha", quando V. procura pela vaquinha de brinquedo sem encontrá-la. Neste momento, a criança utiliza, conforme anteriormente já destacado, enunciado complexo quando comparado àqueles utilizados na rejeição/recusa.

Em Francês, a ausência é expressa a partir de marcadores simples como "non" e expressões mais complexas como "a plus" em "y a plus p(I)us poussin" (não há mais pintinhos), quando, por exemplo, M. procura por pintinhos de pelúcia aos 19 meses. Posteriormente, a criança utiliza expressões com o marcador "pas" (II y a pas - y a pas toboggan - não tem tobogã, aos 25 meses) e combinações com outros itens lexicais "y en a pas" e "y a plus" (não há, não há mais). Ressalta-se que o pronome en é utilizado para substituir quantidades e verbos regidos pela preposição de, enquanto o pronome y é utilizado para substituir construções regidas por à + substantivo comum ou à/en + nome de lugar.

A função expectativas insatisfeitas não surgiu nos registros em Português. Em Francês, ela foi inicialmente expressa por meio do marcador "non", sendo muitas vezes utilizada quando a criança não conseguia realizar determinada ação. Sua primeira expressão 
foi registrada aos 19 meses, quando $M$. tentava subir em uma cadeira para alcançar o computador sobre a mesa, sem sucesso. O marcador "pas" surge aos 23 meses em enunciado complexo "un liv(r)e j'arrive pas à attraper mon yy" (um livro eu não consigo alcançar meu yy), quando M tenta alcançar o livro na prateleira. A expressão "j'arrive pas" (eu não consigo) surge aos 25 meses, em expressão de inabilidade muito semelhante à do adulto.

Negações epistêmicas surgem nas produções da criança brasileira aos 29 meses por meio das expressões "num sei" e "a num sei mamãe". A respeito da partícula negativa "num", Ramos (2006) sugere que o Português Brasileiro passa atualmente por processo de mudança semelhante àquele que desencadeou o padrão de negação em Francês. Nesta direção, o autor observa duas formas, uma "plena" (não) e outra "reduzida" (num) do marcador de negação, que surgiria em três organizações distintas em Português: negação pré-verbal, pré-verbal e pós-verbal e negação pós-verbal. Fundamentando seu ponto de vista, Ramos (2006) explana, a partir de seus dados, que a partícula num constitui de fato forma "fraca" ou "reduzida" do marcador de negação, pois não ocorre em posição final na sentença, mas somente pré-verbal (posição dos pronomes átonos) e em co-ocorrência com outros marcadores de negação (presença do item pleno não na mesma sentença e/ou presença de quantificadores do tipo "ninguém", "nada" na mesma sentença). Ramos (2006) conclui que o Português passa por processo de transformação semelhante ao do Francês, com "gramaticalização" da negação pré-verbal e surgimento de uma negação adverbial pós-verbal.

Também em nossos dados, a forma "reduzida" num surge somente na negação pré-verbal. Ressalta-se que os dados aqui analisados integram o dialeto do Português Brasileiro, que apresenta negação pós-verbal (nordestino). Em outros dialetos, não se observa esta queda da negação pré-verbal.

Nos dados de M., observamos inicialmente o enunciado "sais pas" como forma de expressão da negação epistêmica aos 19 meses de idade. Destaca-se ausência do pronome pessoal je e do marcador de negação "ne" nesta sentença. Enquanto a frase "je sais pas" (com a presença do pronome pessoal) surge aos 26 meses, a partícula "ne" (je ne sais pas) não surge em nenhum momento nos dados analisados. Ressalta-se, entretanto, que no Francês falado atualmente, de fato, a partícula ne já não é produzida, levando à construção da hipótese de que a negação em Francês está em processo de mudança (ASHBY, 2001). Ainda analisando as mudanças e complexificações dos enunciados de $\mathrm{M}$, observa-se que aos 27 meses ela produz enunciados como "moi je sais pas chanter" (eu não sei cantar) acrescentando predicado por meio do qual especifica aquilo que ela afırma "não saber". Aos 28 meses, ela produz negações epistêmicas sobre o desconhecimento de terceiros, neste caso de seu irmão mais novo com apenas poucos meses de vida - Côme i(I) sait pas encore parler (ele não sabe ainda falar). Deste modo, realiza suposições e afirmações sobre terceiros e não só sobre si mesma. 
No que diz respeito à função proibição/comando, esta surge nas produções da criança brasileira quando ela repete proibições enunciadas por seu tio "é não abi a boca" e "assim não" aos 30 meses de idade. Nos dados de M., as proibições são majoritariamente produzidas por meio do uso da partícula "pas" - "pas là faut me faire au photo" (não aqui não pode tirar minha foto) aos 28 meses, quando proíbe a observadora de realizar filmagens na rua. Destaca-se que neste momento a criança utiliza o "pas" em posição não canônica (antes do verbo), quando na verdade ele deveria ser utilizado após o verbo. Entretanto, no mesmo trecho já é possível observar a utilização do "pas" de maneira adequada - "on fait pas t'as pas I(e) droit de de filmer moi mm euh mm euh dans la rue" (não se faz você não tem o direito de me filmar na rua).

Em Português, a oposição/correção é majoritariamente produzida por meio do marcador "não" (sozinho ou em repetição), bem como por enunciados complexos que buscam negar de maneira explícita o elemento afirmado pela mãe. Por exemplo, aos 29 meses ,V. produz a negação "nene foi não (em)bora", após a mãe afirmar que a chupeta da criança havia "ido embora", e "não não não vô parece um um um pinóquio não" aos 31 meses, quando a mãe afırma que ele vai parecer o Pinóquio se mentir, explicitando em seu enunciado um predicado que repete uma afirmação anterior da mãe, mas precedido por negação. Nas produções de M., a oposição é também produzida a partir do marcador "non". Posteriormente, a criança introduz o "pas" também se opondo a afırmações do adulto como, por exemplo, "i(I) dort pas" (ele não está dormindo), produzida pela criança aos 25 meses de idade, em oposição à afirmação da observadora de que o ursinho de pelúcia estava dormindo.

Por fim, a função negação funcional não foi observada nos dados registrados da criança brasileira. Nos dados de $\mathrm{M}$, esta função foi majoritariamente produzida a partir do marcador "non", em resposta às perguntas do tipo sim/não de sua mãe. A criança fez também uso de enunciados com o marcador "pas", realizando negações aparentemente a partir de suposições sobre quais seriam as crenças de seu interlocutor, como quando, por exemplo, M. afırma "c'est pas ton bébé" (não é seu bebê) aos 27 meses, em conversa com a observadora sobre suas bonecas, apesar de a observadora não ter dito esta afirmação (de que os bebês/bonecas seriam dela).

De maneira geral, observam-se semelhanças no desenvolvimento das produções das duas crianças como, por exemplo, o aumento progressivo da complexidade das negações produzidas por meio da inclusão de pronomes pessoais em suas sentenças, bem como da introdução de variações nas partículas negativas utilizadas. No que diz respeito às funções utilizadas, observa-se também o surgimento da rejeição/recusa como primeira função produzida pelas duas crianças e o desenvolvimento das funções negativas utilizadas, que passam de reações às ações parentais a proposições negativas nos dois casos (VASCONCELOS; LEITÃO, 2016). Destacam-se, também, diferenças entre as produções das duas crianças que decorrem de especificidades das línguas investigadas. 
Como, por exemplo, as produções de V. que são explicadas a partir de processos atualmente em curso nas negações em Português (uso do num). Assim como na fala de M., a utilização pouco expressiva da partícula negativa ne pode ser também analisada a partir da hipótese de que esta partícula está em curso de desaparecimento no Francês falado atualmente (ASHBY, 2001).

\section{Considerações finais}

A partir do estudo do desenvolvimento da negação durante os primeiros 32 meses de vida de duas crianças, uma brasileira e uma francesa, foi possível discutir questões relacionadas ao processo de aquisição da linguagem. No que diz respeito às funções negativas utilizadas, foi possível observar semelhanças nas produções das duas crianças estudadas, como o surgimento da função rejeição/recusa como a primeira a ser produzida pelas duas crianças, expressa por meio de marcadores simples como "não" e "non". Entretanto, funções mais elaboradas, como ausência/desaparição, foram expressas mais tardiamente, a partir de enunciados complexos quando comparado àqueles utilizados na rejeição/recusa.

De maneira geral, as negações infantis, no caso das duas crianças estudadas, foram inicialmente utilizadas para rejeitar e opor-se às proposições e ações parentais, entretanto, posteriormente (a partir dos 29 meses de idade), as duas crianças começaram a produzir negações epistêmicas, funcionais e de ausência/desaparição, produzindo, portanto, proposições negativas e não somente reagindo às proposições de seus pais. Deste modo, passaram a realizar constatações sobre si mesmas e sobre seu desconhecimento (negação epistêmica) e constatações sobre ausência de objetos do ambiente (ausência/ desaparição). O desenvolvimento das negações infantis é observado, portanto, não somente a partir do aumento de sua complexidade linguística, mas também a partir do desenvolvimento das funções negativas utilizadas, que passam de reações às ações parentais a proposições negativas.

Por volta do segundo ano de vida, a criança começaria a realizar constatações/ afırmações sobre si mesma, sobre seu desconhecimento (je ne sais pas/eu não sei) ou sobre a ausência de objetos do ambiente (j(e) les vois pa/não os vejo/não tem mais), produzindo, portanto, proposições negativas e não somente reações às proposições de seus pais. Vasconcelos e Leitão (2016) realizam observação semelhante a partir da análise de oposições infantis, concluindo que há deslocamento do lugar discursivo atribuído à criança, que deixa de ser posicionada apenas no lugar de oponente, para ocupar também o lugar de proponente na interação, agindo sobre o ambiente a partir de um "ponto de vista próprio". Neste momento, segundo Vasconcelos e Leitão (2016), a criança não só reage conforme as situações criadas pelos pais, mas toma a iniciativa de agir, mobilizando aspectos do ambiente em proposições muitas vezes negativas. 
Destaca-se também o aumento progressivo da complexidade das negações produzidas pelas duas crianças por meio da inclusão de pronomes pessoais em suas sentenças, bem como da introdução de variações nas partículas negativas utilizadas. É importante destacar as diferenças entre as duas crianças estudadas, que decorrem de especificidades das línguas investigadas. Como, por exemplo, o uso da partícula "num" em posição pósverbal em Português enquanto forma "reduzida" do marcador de negação "não" pela criança brasileira (RAMOS, 2006) e utilização pouco expressiva da partícula negativa "ne" pela criança francesa, fenômeno que pode ser também analisado a partir de processo em curso na língua francesa, segundo o qual essa partícula está em curso de desaparecimento no Francês falado atualmente (ASHBY, 2001). Observa-se, deste modo, como análises translinguísticas geram insights interessantes sobre fenômenos que têm lugar a partir de processos específicos de cada língua.

\section{REFERÊNCIAS}

ARMSTRONG, M.; BERGMANN, A.; TAMATI, T. The Prosody of Negation in Brazilian Portuguese. In: BARBOSA, P. A.; MADUREIRA, S.; REIS, C. (org.). Proceedings of the Speech Prosody Conference. Campinas: Editora RG/CNPq, 2008. p. 489-492.

ASHBY, W. J. Un nouveau regard sur la chute du ne en français parlé tourangeau: s' agit-il d'un changement en cours? Journal of French Language Studies, v. 11, n. 1, p. 1-22, 2001.

BEAUPOIL-HOURDEL, P. A multimodal and corpus-based approach to children's expression of refusal and rejection. International conference of the AFLiCO Empirical Approaches to Multi-modality and to Language Variation. Lille, 2013, p. 15-17.

BEAUPOIL-HOURDEL, P.; MORGENSTERN, A.; BOUTET, D. A Child's Multimodal Negations from 1 to 4: The Interplay Between Modalities. In: LEE, C. (org.). Negation and Polarity: Experimental Perspectives. Springer International Publishing, 2016. p. 95-123.

BLOOM, L. M. Language development: form and function in emerging grammars. Cambridge: M.I.T., 1970.

CAMERON-FAULKNER, T.; LIEVEN, E.; THEAKSTON, A. What part of no do children not understand? A usage-based account of multiword negation. Journal of Child Language, v. 34, n. 2, p. 251-282, 2007.

DEL RÉ, A.; HILÁRIO, R. N.; VIEIRA, A.J. Subjetividade, individualidade e singularidade na criança: um sujeito que se constitui socialmente. Bakhtiniana: Revista de Estudos do Discurso, v. 7, n. 2, p. 57-74, 2012. 
DODANE, C.; BEAUPOIL, P.; DEL RÉ, A.; BOUTET, D.; MORGENSTERN, A. The role of gesture and prosody in children's multimodal pathway into negation. In: Sound to Gesture conference (S2G), 2014.

DODANE, C.; MASSINI-CAGLIARI, G. La prosodie dans I'acquisition de la négation: étude de cas d'une enfant monolingue française. ALFA: Revista de Linguística, v. 54, n. 2, p. 335360, 2010.

KOCHAN, A. The acquisition of negation: a Socio-pragmatic Study of a Bilingual Child. Lyon: Ecole Normale Supérieure de Lyon, 2008.

KONOPCZYNSKI, G. Le Langage Emergent: Caractéristiques Rythmiques. Hamburg: Buske Verlag, 1990.

LACHERET-DUJOUR, A.; BEAUGENDRE, F. La prosodie du français. Paris: CNRS. 1999.

LEITÃO, S. Contribuições de Bakhtin e do círculo para os estudos em aquisição da linguagem. In: // Encontro sobre linguagem da criança - sentido, corpo e discurso/I colóquio sobre alfabetização do núcleo de ensino de Araraquara. São Paulo: UNESP, 2012.

MCNEILL, D.; MCNEILL, N. B. What does a child mean when he says 'no'? In: ZALE, E. M. (org.). Proceedings of the conference on language and language behavior. New York: Appleton-Century-Crofts, 1968.

MORGENSTERN, A.; PARISSE, C. The Paris Corpus. Journal of French Language Studies, v. 22, n. 1, p. 7-12, 2012.

PEA, R. The Development Of Negation In Early Child Language. In: OLSON, D. R. (org.). The Social Foundations Of Language \& Thought. New York: W.W. Norton, 1980. p. 156-186.

RAMOS, J. O processo não > num na fala. In: RAMOS, J.; VITRAL, L. (org.). Gramaticalização: uma abordagem formal. Rio de Janeiro: Tempo Brasileiro/UFMG, 2006. p. 119-132.

SCARPA, E. M.; FERNANDES-SVARTMAN, F. Entoação e léxico inicial. Veredas, v. 16, n. 1, p. 38-52, 2012.

VASCONCELOS, A. N. de; LEITÃO, S. Desenvolvimento da protoargumentação na interação adulto-bebê. ALFA: Revista de Linguística, São Paulo, n. 60, p. 119-146, 2016.

WODE, H. Four early stages in the development of L1 negation. Journal of Child Language, Cambridge, v. 4, n. 1, p. 87-102, 1977. 